\title{
Planned Challenge Agent Exposure Route
}

National Cancer Institute

\section{Source}

National Cancer Institute. Planned Challenge Agent Exposure Route. NCI Thesaurus.

Code C161576.

The planned route of exposure for the challenge agent. 